\title{
O SENTIMENTO DE INFÂNCIA NA PERSPECTIVA DE PHILIPPE ARIÈS
}

\section{ARTIGO DE REVISÃO}

COSTA, Lidiane Natalicia ${ }^{1}$

MAHL, Marcelo Lapuente ${ }^{2}$

COSTA, Lidiane Natalicia. MAHL, Marcelo Lapuente. 0 sentimento de infância na perspectiva de Philippe Ariès. Revista Científica Multidisciplinar Núcleo do Conhecimento. Ano 05, Ed. 03, Vol. 08, pp. 31-36. Março de 2020. ISSN: 2448-0959, Link de acesso: https://www.nucleodoconhecimento.com.br/educacao/sentimento-deinfancia

\section{RESUMO}

O estudo trata-se de um recorte do relatório técnico que subsidiou a produção de um material didático sobre os direitos das crianças. O objetivo foi introduzir reflexões sobre o surgimento do sentimento de infância na perspectiva do historiador Philippe Ariès. Como metodologia utilizou-se a pesquisa bibliográfica. Concluiu-se que, embora o trabalho de Ariès tenha recebido muitas críticas devido as fontes simplistas utilizadas para o entendimento da história da criança, o historiador marcou as pesquisas cientificas ao apresentar a infância como um conceito construído na modernidade.

Palavras-Chave: Infância, história, iconografia, Philippe Ariès.

\footnotetext{
${ }^{1}$ Mestra em Tecnologias, Educação e Comunicação/UFU; Especialista em Trabalho Social com Famílias/ Faculdade Católica de Uberlândia; Graduada em Serviço Social/UNITRI.

${ }^{2}$ Doutorado em História. Mestrado em História. Graduação em História.
} 


\section{INTRODUÇÃO}

O panorama histórico da relação da criança com a sociedade permite-nos observar que houve gradativas transformações socioculturais. Logo, o objetivo do trabalho é apresentar a descoberta do sentimento de infância na trajetória do ocidente, a partir das representações iconográficas da Idade Média analisadas pelo ponto de vista do historiador Philippe Ariès e de outros estudiosos que se contrapõem às suas ideias.

O Historiador francês Philippe Ariès foi um dos pioneiros na utilização da fonte iconográfica para analisar as representações que a sociedade medieval fazia de si mesmo. O seu trabalho ajuda muitos pesquisadores, sobretudo das ciências humanas e sociais, nas teorizações sobre a infância.

Ele defendeu que a infância é um conceito construído socialmente na transição da sociedade feudal para a industrial. Essa ideia abriu espaços para várias discussões, sendo apreciada ou refutada, impulsionando um novo campo epistemológico.

\section{ICONOGRAFIA E CONSIDERAÇÕES SOBRE O SENTIMENTO DE INFÂNCIA}

Ariès (1978) contribuiu para a difusão da história da criança mediante a publicação do clássico L'Enfant e la vie familiale sous l'Ancien Régime (A criança e a vida familiar sob o Antigo Regime)[3].

No seu primeiro capítulo, intitulado "O sentimento da infância", a principal fonte utilizada para descrever o percurso da história da criança foram as imagens pintadas, os retratos e figuras imaginadas.

Ariès (1978) retrata a história da infância a partir de um período em que não existia uma preocupação em preservar a sua memória histórica, até porque o sentimento de infância como é conhecido na contemporaneidade ainda não existia, pois trata-se de um período que nem mesmo o nascimento dos bebês era registrado com o rigor que se tem hoje. 
Até o século XII, as crianças quase não apareciam nas representações iconográficas. Já no século XIII, as crianças passaram a ser mais representadas, e o sentimento atribuído às imagens ficou mais próximo do sentimento contemporâneo. Imagens de rapazes mais jovens, na figura de anjos com traços redondos e graciosos, se tornaram frequentes no século XIV.

Os bebês foram bastante representados pela figura do menino Jesus. A princípio as imagens não tinham muitas formas e nem os traços peculiares das crianças. A única diferença em relação ao adulto era o seu tamanho reduzido. À medida que foi aumentando a sua representatividade no dia a dia, as imagens foram ficando mais realistas e sentimentais, inspirando muitas cenas familiares.

Para Ariès (1978), com o tempo, as imagens religiosas, antes restritas à imagem de Jesus, foram abrindo espaço para outras cenas, como o nascimento e a educação da Virgem. Posteriormente, as imagens de infâncias santas foram ganhando outros protagonistas, como, por exemplo, as figuras de São João, São Tiago, filhos das mulheres santas, Maria Zebedeu e Maria Salomé.

Nos séculos XV e XVI, destaca-se o que Airès (1978) chamou de iconografia leiga, nas quais as cenas de gênero e as pinturas anedóticas começaram a substituir as representações estáticas de personagens simbólicas. Nesse contexto, a criança foi exaustivamente representada em atividades cotidianas, juntamente com outras pessoas.

[...] a criança com sua mãe; a criança com seus companheiros de jogos, muitas vezes, adultos; a criança na multidão mas "ressaltada" no colo de sua mãe ou segura pela mão, ou brincando, ou ainda urinando; a criança no meio do povo assistindo aos milagres ou aos martírios, ouvindo prédicas, acompanhando os ritos litúrgicos, as apresentações ou as circuncisões; a criança aprendiz de um ourives, de um pintor etc.; ou a criança na escola [...] (ARIÈS, 1978, p. 21). 
Outro aspecto importante da iconográfica do século XVI foi a representação da imagem da criança que morreu nos retratos. Primeiramente, nas efígies funerárias, as crianças passam a ser representadas nos túmulos de seus professores e, posteriormente, sobre o túmulo de seus pais. Ariès (1978) considera esses fatos como um marco na história do sentimento de infância, pois representaram a importância em conservar a memória da criança que faleceu, modificando o sentimento de insignificância atribuído à criança durante séculos. No século XVI foi muito comum a produção de imagens da família em que as crianças vivas eram representadas ao lado das crianças que morreram.

A partir do século XVII, as famílias começaram a cultivar retratos de seus filhos sozinhos, perpetuando um costume que dura até os dias atuais. As imagens de crianças nuas, "o putto", foram bastante difundidas como uma espécie de nudez decorativa. Essa foi considerada a última fase da iconografia infantil por Ariès (1978). Daí em diante, esse sentimento pela criança foi muito divulgado pelas imagens, possibilitando o desvendamento de uma cultura e dos valores que permearam a infância durante muitos séculos.

Tomar a infância como uma descoberta na ótica de Ariès (1978) não significa negar a existência biológica das crianças, nem mesmo a falta de amor por elas, mas de considerar as transformações no modo como as pessoas, em especial, as famílias, passaram a ver as crianças e reconhecendo nelas a sua condição peculiar diferenciada do adulto.

Dialogando com a obra de Ariès (1978), Kuhlmann Junior (2010), no livro "Infância e Educação Infantil uma abordagem histórica", faz o levantamento de algumas bibliografias sobre a história da infância. Cita de Mause (1975) que, no livro "The history of Childhood", considerou as mudanças nas relações entre pais e filhos como fruto de uma evolução psicogenética ocorrida em sucessivas gerações de pais. Estes procuraram proporcionar novas oportunidades aos seus filhos, essencialmente, buscando reduzir as ansiedades das crianças que, por sinal, também foram vividas por eles mesmos durante as suas infâncias. Essa evolução aconteceria em ritmos diferentes, nas diferentes famílias e classes sociais. 
Ainda tomando como referência de Mause (1975, KUHLMANN JUNIOR, 2010, p.20) acredita que o sentimento e a satisfação das necessidades da infância aconteceram de forma linear, dessa maneira, propõe seis modos de relacionamento das classes sociais mais altas com a infância:

[...] o infanticídio, da Antiguidade ao século IV D.C.; o Abandono, do século IV ao XIII; a Ambivalência, do século XIV ao XVII; a Intrusão ou Intromissão, no século XVIII, a Socialização, do século XIX a meados do século XX; e o Apoio, Colaboração ou Amparo (Helping Mode Ayuda, na trad. Espanhola), iniciado em meados do século XX (KUHLMANN JUNIOR, 2010, p.20).

De acordo com Kuhlmann Junior (2010), são reconhecidos os avanços na área dos cuidados com a criança, porém a visão evolucionista de Mause minimizou as contradições existentes no cuidado com a criança, pois, se hoje esses sujeitos tem direitos garantidos em diferentes níveis, isso não quer dizer que não presenciamos mais o fim dos massacres de crianças e jovens, da exploração, da violência sexual, da fome e dos maus tratos nas intuições educacionais.

Seguindo os seus estudos, Kuhlmann Junior (2010) apresenta outra fonte de consulta que se opõe às ideias de Ariès (1978) e de Mause (1975). Os estudiosos Cambi e Ulivieri (1988, apud KUHLMANN JUNIOR, 2010, p. 21) não concordam em que a infância tenha caráter linear e ascendente, consideram a realidade social e cultural da infância articulada em classes com a presença de, pelo menos, três modelos de infância convivendo ao mesmo tempo. Acreditam em um percurso que vai do cuidado à mitificação da infância, ou seja, ao mesmo tempo em que se tem o crescimento da importância e da valorização da infância, também permanece a rejeição da sua alteridade.

Outro autor que se debruçou sobre o tema da infância foi o Heywood (2004), que, no livro "Uma História da infância: da Idade Média à época contemporânea no ocidente", reuniu pesquisas sobre a história da infância produzidas em diversos países, como Reino Unido, França, EUA, Itália, Rússia entre outros. Com isso, Heywood (2004) 
buscou conhecer as diferentes concepções sobre a infância em vários tempos e lugares, identificando várias "descobertas" da infância.

No livro, reconheceu o trabalho seminal de Ariès, quando afirmou que o mundo medieval ignorava a infância e que o seu trabalho foi aceito com entusiasmo por vários historiadores, psicólogos e, mais ainda, pelos sociólogos.

Em contrapartida, Heywood (2004) demonstra as várias críticas ao trabalho de Ariès (1978), como Flandrin (1964 apud HEYWOOD, 2004, p.24) que ficou maravilhado com a documentação reunida por Ariès, mas preocupado com a fragilidade do seu método. Outro exemplo é Adrian Wilson (1988 apud HEYWOOD, 2004, p.24) que concluiu que o trabalho de Ariès tinha falhas lógicas e "catástrofes metodológicas".

Nesse passo, Heywood (2004), elenca alguns pontos importantes sobre o trabalho de Ariès (1978). Em primeiro lugar, diz sobre a ingenuidade no trato das fontes históricas, sendo que a ausência das crianças na iconografia da Idade Média poderia ser somente uma característica da arte medieval, devido à concentração em temas religiosos; ou porque os artistas estavam mais preocupados em representar o status e a posição dos seus retratos do que a aparência individual das crianças que pareciam mais com adultos; e, por fim, alguns historiadores acreditam que a "descoberta da infância" do ponto de vista artístico poderia estar mais ligada com a imitação dos modelos gregos e romanos.

Em segundo lugar, as críticas a Ariès se referem ao caráter concentrado no presente. Os críticos acreditam que o fato de o autor não ter encontrado evidências de que as pessoas não tinham consciência da peculiaridade da infância no século XII, na Europa medieval, não evidencia que não existisse sentimento de infância, mas poderia existir outra concepção de infância diferente da concepção moderna (HEYWOOD, 2004).

Nesse mesmo sentindo, uma terceira linha de críticos, julgou exagerada a tese de Ariès sobre a completa ausência de qualquer consciência de infância na civilização medieval, demonstrando, por exemplo, que existia algum reconhecimento da 
"natureza específica" da infância nos códigos jurídicos medievais que continham a proteção da herança dos órfãos (HEYWOOD, 2004).

Heywood (2004), seguindo o pensamento de David Archard (1993 apud HEYWOOD, 2004, p.27), admite que, no mundo medieval, existia algum conceito a respeito da infância, mas que as suas concepções eram bem diferentes da infância tal como é conhecida na atualidade.

Então, concluiu se que, embora o trabalho de Ariès tenha recebido muitas críticas, não se pode deixar de introduzir o tema sobre a infância sem mencionar essa obra, pois é possível "aproveitar suas tantas percepções acerca do passado e seguir adiante" (HEYWOOD, 2004, p.27).

Sobre estudar o passado das crianças através de várias fontes, Priori (2012) fala da importância de "dar voz aos documentos históricos, perquirindo-os nas suas menores marcas, exumando-os nas suas informações mais concretas ou mais modestas, iluminando as lembranças mais apagadas" (PRIORI, 2012, p. 249)

Finalizando, Campos (2009) menciona que a noção de infância refere-se a uma produção sociocultural resultada das representações dos adultos acerca dos mais novos. Kuhlmann Junior (2010), por sua vez, argumenta que as crianças não escrevem a sua própria história. A história da criança é uma história sobre criança.

Sendo assim, estuda-se o trabalho de Ariès para rastrear os sinais, indícios e signos que podem ajudar no esclarecimento de um ponto de vista sobre a infância, mas sem a possibilidade de captá-lo em sua integridade.

\section{CONSIDERAÇÕES FINAIS}

Se por um lado, hoje em dia, falamos em um sistema de garantia dos direitos das crianças, no que tange a efetivação desses direitos, entendemos que ainda há um processo longo para percorrer. Logo, este breve estudo propôs uma ação no sentido de "olhar para traz". Introduzimos a multiplicidade de pressupostos que se referem à infância sem esgotar as possibilidades de interpretações. 
Ao refletir sobre a obra de Philippe Ariès, percebemos o tratamento que era oferecido às crianças e temos subsídios para entendermos as representações sociais construídas em torno da infância na modernidade.

Por fim, aqui temos uma leitura para breves reflexões, mas recomendamos o estudo do livro original para outras apreciações.

\section{REFERÊNCIAS}

ARIÈS, Philippe. História social da criança e da família. Tradução: D. Flaksman. Rio de Janeiro: LCT, 1978.

CAMPOS, Raquel Discini. Philippe Ariès: A paixão pela história. In: Cadernos de História da Educação, Uberlândia: EDUFU, v. 11, n. 1 - jan./jun, 2012. p. 269-284.

DEL PRIORI, Mary. A criança negra no Brasil. In: VILELA, Ana Maria Jacó; SATO, Leny. In: Diálogos em psicologia social [online], Rio de Janeiro: Centro Edelstein de Pesquisas Sociais, 2012. p. 232- 253. Disponível em: <http://books.scielo.org>. Acesso em 12/12/2019.

HEYWOOD, Colin. Uma história da infância: da idade média à época contemporânea no ocidente. Porto Alegre: Artmed, 2004.

KUHLMANN JÚNIOR, Moysés. Infância e educação infantil: uma abordagem histórica. Porto Alegre: Mediação, 2010.

3. Publicado pela primeira vez na França, pela Editions Plon, em 1960; e editado no Brasil pela Editora Jorge Zahar, em 1978, sob o título de História Social da Criança e da Família. Alterou definitivamente o conhecimento dos outros sobre o próprio autor e sobre o nosso próprio saber sobre a história das crianças (CAMPOS, 2012).

Enviado: Março, 2020.

Aprovado: Março, 2020. 